\title{
Tumescent mastectomy: the current indications and operative tips and tricks
}

This article was published in the following Dove Press journal:

Breast Cancer - Targets and Therapy

30 March 2017

Number of times this article has been viewed

\author{
Ashraf Khater' \\ Alaa Mazy ${ }^{2}$ \\ Mona Gad² \\ Ola Taha Abd Eldayem ${ }^{2}$ \\ Mohamed Hegazy' \\ 'Department of Surgical Oncology, \\ Mansoura Oncology Center (OCMU), \\ ${ }^{2}$ Anesthesia and Surgical Intensive \\ Care Department, Mansoura \\ University Hospital, Faculty of \\ Medicine, Mansoura University, \\ Mansoura, Egypt
}

Background: Tumescent mastectomy refers to usage of a mixture of lidocaine and epinephrine in a diluting saline solution that makes flaps firm and tense, thus minimizing systemic drugs toxicity and making surgery possible with minimal bleeding. This technique is very useful in elder women and those with American Society of Anesthesiologists; score III and IV. The objective was to establish an alternative safe technique to general anesthesia in some selected mastectomy patients. Patients and methods: Twenty candidate women for total mastectomy and axillary dissection were enrolled and consented to participate. After preparation, an anatomically directed infiltration was made under sedation, using a cocktail of lidocaine, bupivacaine, and epinephrine, followed after 20 minutes by the surgical incision and completion of mastectomy. All intraoperative and postoperative outcomes were recorded.

Results: Although 7 cases required added analgesic medications, no conversion for general anesthesia was recorded. Mean operative time was $81 \pm 15.8$ minutes. Mean blood loss was $95.8 \pm 47.5 \mathrm{~mL}$. There was no recorded intraoperative hemodynamic instability. Postoperative visual analog score was not exceeding 4 till the end of the first 24 hours. Opioids were not required in any case, and the mean dosage of Ketorolac used was $30 \pm 8.75 \mathrm{mg}$. Drains output and the incidence of postoperative complications were acceptable.

Conclusion: We can consider tumescent mastectomy in well-selected patients a safe alternative for performing mastectomy when general anesthesia is hazardous, with minimal blood loss and long lasting postoperative analgesia without an additive effect on the operative time, hospital stay, and intraoperative and postoperative complications.

Keywords: tumescent, mastectomy, anesthesia, lidocaine

\section{Introduction}

Tumescent anesthesia is not a new technique. It has been routinely used in liposuction with a great success. Then, it was transferred to the field of plastic surgery and dermatology. ${ }^{1}$ The concept of tumescent anesthesia depends on using a mix of lidocaine and epinephrine together with sodium bicarbonate in a diluting saline solution that is injected subcutaneously by infiltration till tissues become firm and tense, and this is the meaning of the word "tumescent". ${ }^{2}$ The reported safety of this technique was guaranteed by many authors due to slow systemic absorption of the lidocaine owing to the vasoconstrictive effect of epinephrine and partly due to vessel compression by hydrostatic effect of the solution itself. ${ }^{2}$ The peak plasma level of lidocaine was reported after 4-12 hours, and the clinical local analgesia was reported to last for 18-24 hours. ${ }^{3,4}$ The use of this technique in mastectomy with or without reconstruction
Correspondence: Ashraf Khater

Department of Surgical Oncology, Mansoura Oncology Center (OCMU), Faculty of Medicine, Mansoura University, 60 Gomhoria Street, Mansoura,

$355 \mathrm{II}$, Egypt

Tel +20502358021

Email dr.ashrafkhater@yahoo.com 
was limited and was reserved for elderly patients with comorbidities for whom general anesthesia is hazardous. ${ }^{5}$ In spite of emergence of regional anesthetic techniques such as epidural anesthesia, ${ }^{6}$ the intercostal blocks, ${ }^{7}$ and the paravertebral block (PVB), ${ }^{8}$ many problems were associated with these techniques as failure, risk of complications including pneumothorax, and accidental dural puncture, beside the need for specific skills and time consumption. ${ }^{7}$ The aim of the current study is to address the suitable patients and the proper technique for doing mastectomy entirely by using the tumescent anesthesia.

\section{Patients and methods}

\section{Patient selection}

Twenty patients were enrolled into this prospective study that was carried out in the period from January 2014 until September 2015 after approval of the Mansoura Faculty of Medicine local institutional review board (Code number; R/16.06.03) with fulfillment of the criteria of Helsinki Declaration. The patients' informed written consent to participate in the study was obtained after explanation of the technique and its possible hazards. This study included all patients with operable breast carcinoma who were candidates for total mastectomy with axillary clearance and were risky for general anesthesia, which was based on American Society of Anesthesiologists (ASA) scoring system around III-IV. ${ }^{9}$

Patients with orthopnea, cardiomyopathy, poorly controlled arrhythmia, renal impairment, pheochromocytoma, hyperthyroidism, history of myocardial infarction or cerebral stroke, bedridden patients, those with advanced or metastatic local disease, those with prior chemotherapy or chest irradiation, those on long-term steroid therapy, noncompliant patients, and those with hypersensitivity to the tumescent cocktail were excluded from this study.

\section{Method}

\section{Patient preparation}

All demographic data were collected; standard laboratory investigations, ECG, ECHO cardiography, and other requested investigations according to patient comorbidities were made. The technique, its hazards, and the possibility of conversion to general anesthesia was explained before taking consent from patients. Premedication with midazolam 1-3 mg and dextrose $5 \%$ at a rate of $125 \mathrm{~mL} / \mathrm{h}$ was given preoperatively starting at $6 \mathrm{am}$. Cardiovascular drugs were given, except for angiotensin receptor blockers and angiotensin-converting-enzyme inhibitors.

\section{The tumescent technique}

The tumescent cocktail

The volume of infiltrate was roughly estimated as two times the volume of the breast. ${ }^{10}$ The breast volume was estimated using the following equation; Breast volume $=0.973 \times(\text { breast circumference } / 6.28)^{3}{ }^{11}$

Components:

- Lidocaine $2 \%$ in a total maximum dose of $20 \mathrm{mg} / \mathrm{kg}$. The estimated safe dosage for tumescent lidocaine was shown to be at least $35 \mathrm{mg} / \mathrm{kg}$. ${ }^{4}$

- Bupivacaine $0.5 \%$ was added at a dose of $2 \mathrm{mg} / \mathrm{kg}$ to prolong the postoperative analgesic effect. ${ }^{12}$ A study by Swanson confirmed the safe use of bupivacaine in doses up to $550 \mathrm{mg}$ (up to $9.2 \mathrm{mg} / \mathrm{kg}$ ). ${ }^{13}$ As a mixture, we used lower doses of lidocaine and bupivacaine to avoid additive toxicity.

- Epinephrine $2 \mathrm{mg}$ of 1/1,000 epinephrine/L of Ringer lactate solution. ${ }^{5}$

\section{Tumescent fluid infiltration and surgical procedure}

After establishing standard monitoring, local infiltration was done using a blunt tipped liposuction needle with $5 \mathrm{~mm}$ gauge (Figure 1A), which was introduced through a very small skin snip under a mild sedation using a combination of propofol (1 mg/kg intravenous [IV] bolus, with $0.1 \mathrm{mg} / \mathrm{kg} / \mathrm{min}$ infusion), midazolam ( $0.03 \mathrm{mg} / \mathrm{kg} \mathrm{IV})$, and fentanyl ( $1 \mu \mathrm{g} / \mathrm{kg} \mathrm{IV})$ as tolerated by the patient. ${ }^{5}$

\section{Two infiltrations were used}

- The first entailed a wide subcutaneous infiltration of the surgical site, thereby creating a tumescence area till the breast became tense and blanched (Figure 1B).

- The second technique was a field block to infiltrate the piercing intercostal nerves and subglandular space. This was made by infiltration under the superior skin flap in the subdermal plane along the caudal border of the clavicle (to block infraclavicular nerves), along the midaxillary line extending high in the axilla to block the lateral cutaneous branches of the second to seventh intercostal nerves (Figure 1C), under the inferior skin flaps, along the sternum in the subdermal planes to block the anterior intercostal nerves, and finally through the retromammary space infiltrating nerves under the pectoral fascia.

- The breast, overlying skin, and fascia of the pectoralis major muscle were removed en bloc using the scalpel dissection with cauterization of bleeding points by 
A

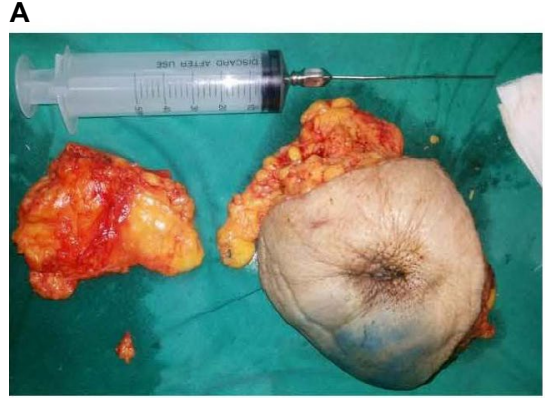

C

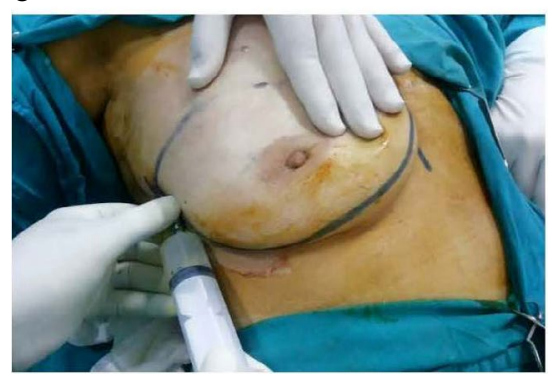

B

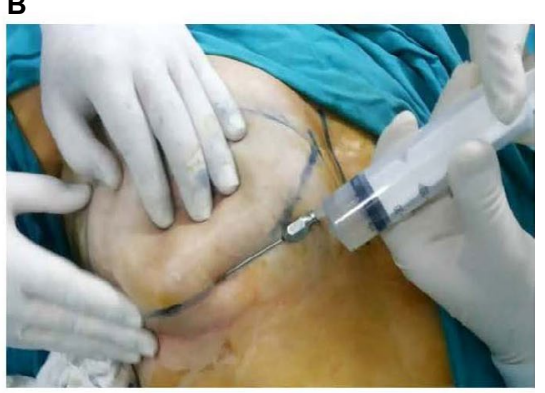

D

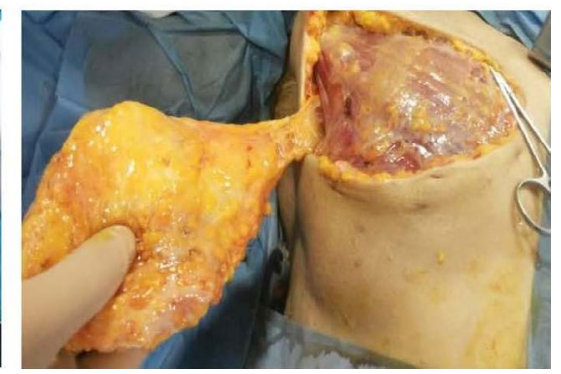

Figure I The tumescent process.

Notes: Photos from more than one case showing; (A) the used cannula and syringe, (B) infiltration of the lower flap with tumescence, $(\mathbf{C})$ Infiltration of the lateral flap and axilla, (D) Nearly bloodless field.

diathermy, and this was followed by a limited axillary dissection of levels I and II.

- Usually the incision was started 15 minutes after the end of infiltration to allow a proper anesthesia and analgesia. ${ }^{3}$

- We used an oxygen face mask in all patients with ischemic heart disease (IHD) and when $\mathrm{SaO}_{2}$ was below 92\%.

\section{Intraoperative management and measurements}

Clinical signs suggesting insufficient analgesia (pain, movement, or rise in blood pressure or heart rate $>20 \%$ of the basal) were managed if necessary by fentanyl $25 \mu \mathrm{g}$ increments, extra infiltration, propofol increments of $50 \mathrm{mg}$, or midazolam 1-2 mg, dexmedetomidine $1 \mu \mathrm{g} / \mathrm{kg}$ IV bolus over 10 minutes followed by infusion $0.2-0.5 \mu \mathrm{g} / \mathrm{kg} / \mathrm{h}$ as required. Most of the patients requested this with axillary dissection. In the presence of excessive pain, movements, hemodynamic instability, or difficult ventilation, the technique was considered as failed and general anesthesia was conducted, airway was maintained by a suitable sized laryngeal mask (LMA) with sevoflurane inhalation. The mean blood pressure, heart rate, and oxygen saturation were recorded during the procedure (Figure 2).

- Total intraoperative requirements of propofol, fentanyl and midazolam, and dexmedetomidine were recorded, together with the conversion rate to general anesthesia.

- Accordingly the tumescent anesthesia index was calculated as: The number of episodic adding propofol, fentanyl, midazolam, dexmedetomidine, and extra infiltration/duration of surgery in hours.

- Infiltration time, the operative time, and the amount of blood loss were recorded.

- All cases were operated by a single surgeon and surgeon satisfaction score from 0-10 was recorded.

- Toxicity signs of local anesthetics or epinephrine side effects were assessed and managed according to ASRA recommendations (American Society of Regional Anesthesia). ${ }^{14}$ The pulse, blood pressure, and oxygen saturation were recorded initially, then every 5 minutes during infiltration, then every 30 minutes. Hypotension was managed by boluses of ephedrine $5 \mathrm{mg}$ and additional IV fluids. Hypertension was managed by increments of $25 \mu \mathrm{g}$ fentanyl, dexmedetomidine $1 \mu \mathrm{g} / \mathrm{kg}$ over $10 \mathrm{~min}$, and nitroglycrine $0.5-10 \mu \mathrm{g} / \mathrm{kg} /$ minute. Bradycardia was managed by $0.5 \mathrm{mg}$ atropine, while tachycardia was managed as hypertension plus propranolol $1 \mathrm{mg}$ if required. Other dysrhythmias were managed according to their specific types. Myocardial ischemia was assessed intraoperatively by ECG and postoperatively by ECG for all patients within 24 hours or in those with with clinical symptoms.

\section{Postoperative management}

The following parameters were recorded. 
$\square \mathrm{SaO}_{2}=\mathrm{MBP} \square \mathrm{HR}$

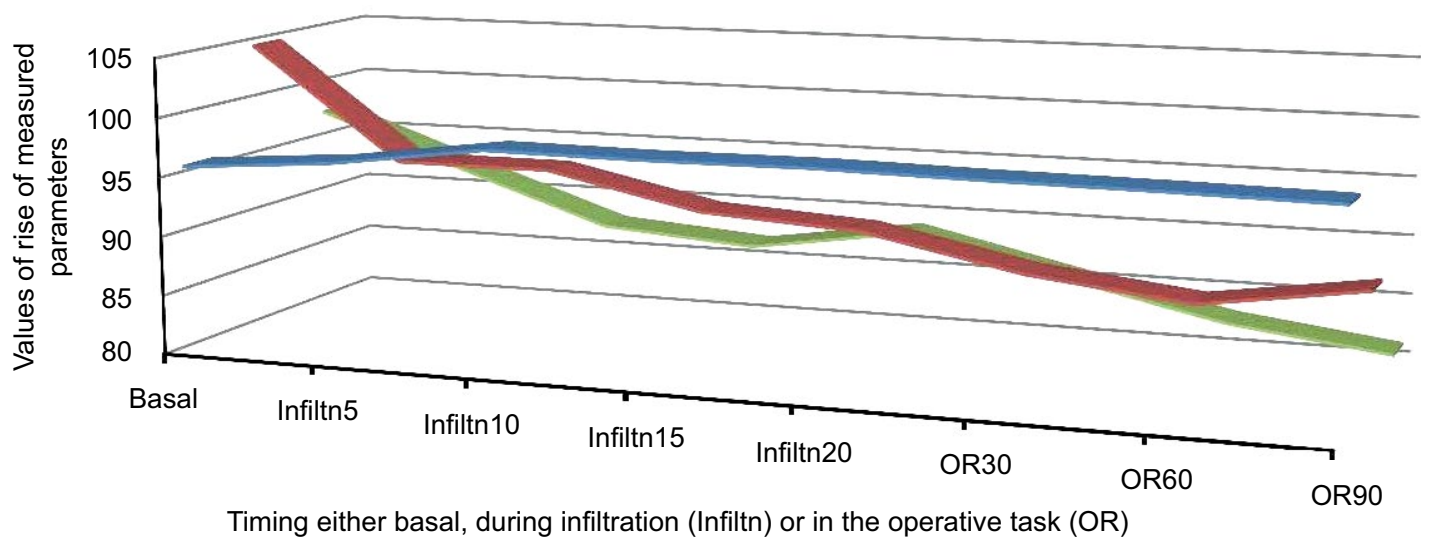

Figure 2 The mean blood pressure, heart rate, and oxygen saturation were recorded during the tumescent procedure: basal, infiltration, and dissection. Notes: Data are in mean values.

- The total mean of postoperative vital signs (mean blood pressure, heart rate, and respiratory rate) in the first 24 hours.

- ECG after 24 hours or in those with appearance of ischemic symptoms.

- Pain assessment every 4 hours using the 10 points visual analog score (VAS).

- The time till the first request for analgesia.

- Postoperative analgesia, which was given on patient request or at VAS $\geq 4$ as ketoralc $30 \mathrm{mg}$ and paracetamol $1 \mathrm{~g}$, and if pain was not controlled, nalbuphine $5 \mathrm{mg}$ increments were given until VAS is $\leq 2$.

- Total analgesic requirements.

- Rate of anesthetic complications as hypo or hypertension, dysrhythmia, or hypoxia.

- The amount of drain output every day for 3 days.

- Hematoma, seroma, flap necrosis, wound infection, and wound dehiscence.

- The length of hospital stay.

- Patient satisfaction on a score of 0-10.

\section{Results}

Patient demographic and clinical data are shown in Table 1. The operative data are shown in Table 2 and Figure 2. Postoperative outcomes are demonstrated in Table 3 and Figure 3. There was no reported complaint of chest pain, and there were no ECG changes after 24 hours. The mean postoperative VAS did not exceed 4 within the first 24 hours measurement (Table 3). There were 6 cases of postoperative mild seroma (30\%) that were managed successfully with repeated aspiration. Simple hematoma occurred in three
Table I Demographic and clinical data $(n=20)$

\begin{tabular}{lll}
\hline Parameter & Mean \pm SD & Range \\
\hline Age $(\mathrm{yr})$ & $60 \pm 7.3$ & $49-75$ \\
$\mathrm{BMI}\left(\mathrm{kg} / \mathrm{m}^{2}\right)$ & $28 \pm 4.5$ & $26-32$ \\
Breast volume $\left(\mathrm{cm}^{3}\right)$ & $378 \pm 10 \mathrm{I}$ & $235-550$ \\
Maximum tumor size $(\mathrm{cm})$ & $4 \pm 0.32$ & $2.5-5$ \\
Positive lymph nodes & $4 \pm 0.75$ & $0-10$ \\
ASA score & $3 \pm 0.75$ & $3-4$ \\
& Number/total & Percentage \\
Hypertension & $13 / 20$ & 65 \\
DM & $7 / 20$ & 35 \\
IHD & $5 / 20$ & 25 \\
AF & $1 / 20$ & 5 \\
COPD & $1 / 20$ & 5 \\
Cerebral strokes & $2 / 20$ & 10 \\
Cardiomyopathy & $1 / 20$ & 5 \\
Hepatic disease (Child B) & $2 / 20$ & 10 \\
\hline
\end{tabular}

Abbreviations: ASA, American Society of Anesthesiologists; BMI, body mass index; DM, diabetes mellitus; IHD, ischemic heart disease; COPD, chronic obstructive pulmonary disease; $\mathrm{AF}$, atrial fibrillation; SD, standard deviation.

patients (15\%), and all passed smoothly with conservative measures. There was one case of partial flap necrosis of less than $15 \%$, which was treated by simple debridement at the outpatient clinic, and there was one case of minor wound gap that was treated by secondary closure after 2 weeks. Figure 3 shows a postoperative photo of one of the cases that was operated with the technique.

\section{Discussion}

Tumescent anesthesia is not a new technique, but it gained popularity through its wide use in liposuction techniques. ${ }^{2,15}$ In the field of breast surgery, it was popularized 
Table 2 Operative data $(n=20)$

\begin{tabular}{lll}
\hline Parameter & Mean \pm SD & Range \\
\hline Total operative time $(\mathrm{min})$ & $81 \pm 15.8$ & $60-110$ \\
Infiltration time $(\mathrm{min})$ & $14.8 \pm 4$ & $10-20$ \\
Tumescent volume $(\mathrm{mL})$ & $1,500 \pm 293.5$ & $1,000-2,100$ \\
Blood loss $(\mathrm{mL})$ & $95.8 \pm 47.5$ & $70-180$ \\
Mean doses of intraoperative medications: & & \\
- Propofol $(\mathrm{mg})$ & $310 \pm 69.7$ & $150-400$ \\
- Fentanyl $(\mu \mathrm{g})$ & $110.7 \pm 39.5$ & $70-200$ \\
- Midazolam $(\mathrm{mg})$ & $1.9 \pm 1.5$ & $0-5$ \\
- Dexmedetomidine $(\mu g)$ & $11.5 \pm 228$ & $0-80$ \\
& Number & Percentage \\
Number of patients required intraoperative & $7 / 20$ & 35 \\
anesthetic medications & & 0 \\
Conversion rate to general anesthesia & $0 / 20$ & 0 \\
\hline
\end{tabular}

Table 3 Postoperative outcomes $(n=20)$

\begin{tabular}{|c|c|c|}
\hline Parameter & Mean \pm SD & Range \\
\hline \multicolumn{3}{|l|}{ Mean postoperative vitals: } \\
\hline - Heart rate $(\mathrm{b} / \mathrm{min})$ & $82 \pm 6.5$ & $65-90$ \\
\hline - Mean blood pressure (mmHg) & $85 \pm 8.5$ & $70-95$ \\
\hline - Respiratory rate (br/min) & $22 \pm 4.75$ & $20-25$ \\
\hline \multicolumn{3}{|l|}{ Postoperative VAS $(0-10)$ at: } \\
\hline - $4 \mathrm{~h}$ & $2.5 \pm 0.75$ & $2-5$ \\
\hline - $8 \mathrm{~h}$ & $3.3 \pm 0.5$ & $2-4$ \\
\hline - $12 \mathrm{~h}$ & $3.4 \pm 1.5$ & $3-5$ \\
\hline - $16 \mathrm{~h}$ & $3.6 \pm 0.5$ & $2-5$ \\
\hline - $20 \mathrm{~h}$ & $2.9 \pm 0.65$ & $2-4$ \\
\hline - $24 \mathrm{~h}$ & $2.6 \pm 0.5$ & $2-5$ \\
\hline Time till the first request of analgesia $(\mathrm{h})$. & $6 \pm 0.5$ & $3-8$ \\
\hline \multicolumn{3}{|c|}{ Postoperative analgesic use in the first $24 \mathrm{~h}$ : } \\
\hline - Ketorolac (mg) & $30 \pm 8.75$ & $0-45$ \\
\hline - Paracetamol (g) & $\mathrm{I} \pm 0.65$ & $0-2$ \\
\hline - Nalbuphine (mg) & 0 & 0 \\
\hline Drain outcome in Ist $3 \mathrm{~d}(\mathrm{~mL})$ & $330 \pm 58$ & $150-390$ \\
\hline Hospital stay $(d)$ & $2 \pm 0.75$ & $\mathrm{I}-4$ \\
\hline Surgeon satisfaction score & $8 \pm 0.75$ & $7-10$ \\
\hline \multirow[t]{2}{*}{ Patient satisfaction score } & $6 \pm 0.8$ & $5-9$ \\
\hline & Number & Percentage \\
\hline \multicolumn{3}{|l|}{ Postoperative wound complications: } \\
\hline - Seroma & $6 / 20$ & 30 \\
\hline - Hematoma & $3 / 20$ & 15 \\
\hline - Partial flap necrosis & $1 / 20$ & 5 \\
\hline - Wound gap & $1 / 20$ & 5 \\
\hline
\end{tabular}

Abbreviations: VAS, visual analog score; SD, standard deviation.

by Worland ${ }^{16}$ in 1996 , when he observed its successful use in abdominoplasties, but it was reserved for elderly patients and those with poor anesthetic risk, especially those with ASA score III or IV. ${ }^{5}$ Although epidural anesthesia, intercostal block, and paravertebral block are used in these situations, all are technically demanding, not free of complications, and still have a failure rate. ${ }^{15}$ The

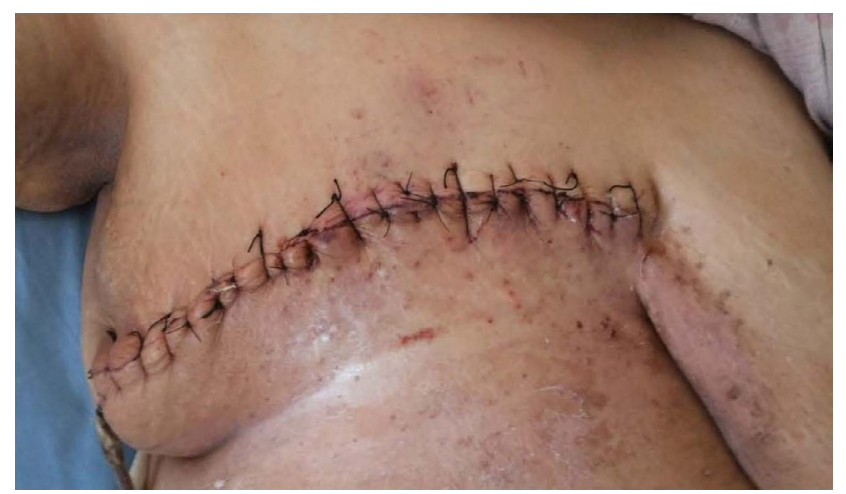

Figure 3 Four days postoperative view of a patient who underwent total mastectomy and axillary clearance by the tumescent technique.

tumescent technique depends on blockade of the noxious stimuli from nerve endings at the site of incision through infiltration of tissues around the nerve endings. ${ }^{17}$ The most commonly used drug is lidocaine; ${ }^{5}$ however, some authors add bupivacaine to prolong the analgesic effect. ${ }^{18}$ To avoid the systemic toxicity of lidocaine absorption, two options were undertaken: the first was epinephrine that was added to constrict the blood vessels, and the second option was the hydrostatic pressure of the tumescent diluting saline which further compress vessels. By this technique, a very high concentration of lidocaine, up to $55 \mathrm{mg} / \mathrm{kg}$, was used safely without significant complications. ${ }^{19}$ There was a theoretical risk of epinephrine toxicity due to about 15 minutes delay of onset of vessels' constriction with risk of elevated blood pressure, tachycardia, or arrhythmias. ${ }^{20}$ Actually this was not recorded, partly due to the saline diluting effect and partly due to the compressed and constricted vessels by the tumescent fluid mechanical effect, which leads to slow absorption of epinephrine. Another advantage of the vasoconstrictive mechanism partly due to epinephrine and partly due to the hydrostatic pressure is the significantly minimized blood loss with nearly bloodless field (Figure 1D) (Table 2). ${ }^{21,22}$ The use of propofol in this study was not for anesthetic purpose but it was as a sedative to enable the process of tumescent fluid infiltration. In our study, we used combined flaps infiltration and anatomically based regional local nerve infiltration. This is to ensure total analgesia, but it was very important to wait for nearly 15 minutes for the cocktail to work before starting the incision. ${ }^{3}$ Actually, the time consumed in infiltration was compensated by the ease of mastectomy and the minimal blood loss (Table 2). Although, we described the use of local nerve blocks in this study, this does not mean a mastectomy with a field block; however, during tumescent infiltration, we focused on the regions of the sensory cutaneous nerves such as the infraclavicular 
and intercostal nerves. The tumescent technique is not just a nerve blockade, but it entails use of a cocktail that minimizes bleeding and blocks the sensory stimuli from every point along the mastectomy incision. In most of our cases, aid was provided with analgesic medications (Table 2), but there was no conversion to general anesthesia in any case. There was a high surgeon and patient satisfaction score, and this reflects the degree of success of the technique. In this study, most of patients were hemodynamically stable throughout the procedure with accepted vitals (Table 2), the same was recorded in the postoperative period with noticeable dramatic analgesic postoperative effect, which was reflected as the minimal requirement of postoperative analgesia (Table 2). In the literature, there is an argument about the impact of this technique on the incidence of postmastectomy complications; some showed an increased rate of complications in the tumescent group, ${ }^{21,23}$ while others showed an increase of the native breast envelop necrosis. ${ }^{24}$ However, other studies showed that the technique did not pose any additive effect to these complications. ${ }^{25,26}$ One of the interesting findings in a study by Johnson and his coworkers $^{27}$ that was reported in 2008 found lidocaine to provide a dose-dependent inhibition of bacterial growth, with growth of gram-negative organisms being inhibited more than gram-positive organisms. In our study, there were few postoperative complications that passed smoothly with conservative treatment (Table 2), and most of patients were discharged after the average hospital stay period. Some of the learned surgical tips are: infiltration under propofol sedation markedly alleviates patient apprehension and improves patient trust and confidence, it is very important to infiltrate the axilla well as this area is a common source of intraoperative painful stimuli. The cocktail decreases need for diathermy use, which is a source of painful stimuli or muscle contractions that irritates the patient. This technique can serve well for patients who would otherwise be canceled from operation and avoids the hazards and cost of general anesthesia and opioids that are commonly used for pain control in postmastectomy settings.

\section{Conclusion}

We can consider tumescent mastectomy in well-selected patients a safe alternative for mastectomy when general anesthesia is hazardous, with minimal blood loss and long lasting postoperative analgesia without an additive effect on the operative time, hospital stay, and intraoperative and postoperative complications.

\section{Disclosure}

The authors report no conflicts of interest in this work.

\section{References}

1. Beck-Schimmer B, Pasch T. Tumescent technique for local anesthesia. Anasthesiol Intensivmed Notfallmed Schmerzther. 2002; 37(2):84-88.

2. Conroy PH, O'Rourke J. Tumescent anaesthesia. Surgeon. 2013;11(4): 210-221.

3. Klein JA. The tumescent technique. Anesthesia and modified liposuction technique. Dermatol Clin. 1990;8(3):425-437.

4. Klein JA. Tumescent technique for regional anesthesia permits lidocaine doses of $35 \mathrm{mg} / \mathrm{kg}$ for liposuction. J Dermatol Surg Oncol. 1990; 16(3):248-263.

5. Carlson GW. Total mastectomy under local anesthesia: the tumescent technique. Breast J. 2005;11(2):100-102.

6. Lynch EP, Welch KJ, Carabuena JM, Eberlein TJ. Thoracic epidural anesthesia improves outcome after breast surgery. Ann Surg. 1995; 222(5):663.

7. Atanassoff PG, Alon E, Weiss BM. Intercostal nerve block for lumpectomy: superior postoperative pain relief with bupivacaine. J Clin Anesth. 1994;6(1):47-51.

8. Terheggen MA, Wille F, Borel Rinkes IH, Ionescu TI, Knape JT. Paravertebral blockade for minor breast surgery. Anesth Analg. 2002; 94(2):355-359.

9. Daabiss M. American Society of Anaesthesiologists physical status classification. Indian J Anaesth. 2011;55(2):111-115.

10. Novoa JC. Tumescent Anesthetic Breast Surgery (TABS): breast augmentation surgery in an office-based surgical center. In: Mugea T.T, Shiffman M.A, editors. Aesth Surg Breast. Berlin Heildelberg: Springer; 2015:107-119.

11. El-Oteify M, Megeed HA, Ahmed B, El-Shazly M. Assessment of the breast volume by a new simple formula. Indian J Plast Surg. 2006; 39(1):13.

12. Jabs D, Richards BG, Richards FD. Quantitative effects of tumescent infiltration and bupivicaine injection in decreasing postoperative pain in submuscular breast augmentation. Aesth Surg J. 2008;28(5): $528-533$.

13. Swanson E. Prospective study of lidocaine, bupivacaine, and epinephrine levels and blood loss in patients undergoing liposuction and abdominoplasty. Plast Reconstr Surg. 2012;130(3):702-722.

14. Neal JM, Mulroy MF, Weinberg GL; American Society of Regional Anesthesia and Pain Medicine. American Society of Regional Anesthesia and Pain Medicine checklist for managing local anesthetic systemic toxicity: 2012 version. Reg Anesth Pain Med. 2012; 37(1):16-18.

15. Batra RK, Krishnan K, Agarwal A. Paravertebral block. J Anaesthesiol Clin Pharmacol. 2011;27(1):5-11.

16. Worland RG. Expanded utilization of the tumescent technique for mastectomy. Plast Reconstr Surg. 1996;98(7):1321.

17. Scott NB. Wound infiltration for surgery. Anesthesia. 2010;65:67-75.

18. Paik AM, Daniali LN, Lee ES, Hsia HC. Local anesthetic use in tumescent liposuction: an American Society of Plastic Surgeons survey. Ann Plast Surg. 2015;74(2):145-151.

19. Ostad A, Kageyama N, Moy RL. Tumescent anesthesia with a lidocaine dose of $55 \mathrm{mg} / \mathrm{kg}$ is safe for liposuction. Dermatol Surg. 1996;22(11): 921-927.

20. Klein JA. Anesthetic formulation of tumescent solutions. Dermatol Clin. 1999;17(4):751-759.

21. Abbott AM, Miller BT, Tuttle TM. Outcomes after tumescence technique versus electrocautery mastectomy. Ann Surg Oncol. 2012;19(8): 2607-2611.

22. Joseph AY, Bloch R, Yee S. Simple anesthesia for simple mastectomies. Breast Cancer Res Treat. 2003;77:189-191. 
23. Seth AK, Hirsch EM, Fine NA, et al. Additive risk of tumescent technique in patients undergoing mastectomy with immediate reconstruction. Ann Surg Oncol. 2011;18(11):3041-3046.

24. Chun YS, Verma K, Rosen H, et al. Use of tumescent mastectomy technique as a risk factor for native breast skin flap necrosis following immediate breast reconstruction. Am J Surg. 2011;201(2): $160-165$.
25. Khavanin N, Fine NA, Bethke KP, et al. Tumescent technique does not increase the risk of complication following mastectomy with immediate reconstruction. Ann Surg Oncol. 2014;21(2):384-388.

26. Vargas CR, Koolen PG, Ho OA, et al. Tumescent mastectomy technique in autologous breast reconstruction. J Surg Res. 2015;198(2):525-529.

27. Johnson SM, Saint John BE, Dine AP. Local anaesthetics as antimicrobial agents: a review. Surg Infect. 2008;9:205-213.
Breast Cancer - Targets and Therapy

\section{Publish your work in this journal}

Breast Cancer - Targets and Therapy is an international, peerreviewed open access journal focusing on breast cancer research, identification of therapeutic targets and the optimal use of preventative and integrated treatment interventions to achieve improved outcomes, enhanced survival and quality of life for the cancer patient

\section{Dovepress}

The manuscript management system is completely online and includes a very quick and fair peer-review system, which is all easy to use. Visit http://www.dovepress.com/testimonials.php to read real quotes from published authors.

Submit your manuscript here: https:/www.dovepress.com/breast-cancer---targets-and-therapy-journal 